\title{
STRATEGI KOMUNIKASI PEMASARAN DIGITAL PADA PRODUK KULINER TRADISIONAL
}

\author{
Ida Ri'aeni \\ Prodi Ilmu Komunikasi, Fakultas Ilmu Sosial dan Ilmu Politik \\ Universitas Muhammadiyah Cirebon \\ Jl. Fatahillah No.40, Cirebon \\ Email: ida.riaeni@umc.ac.id
}

\begin{abstract}
Digital marketing communication strategy is a brand promotion activity that has been planned and arranged systematically. Its strategy builds brand interaction within its users. This marketing strategy is also carried out by several traditional Cirebon culinary business people. The purpose of this study was to analyze the marketing communication strategy in the three producers of Cirebon savory sticky rice, namely: Ketan Gurih (Sticky Rice), Mrs. Yudi; Ketan Gurih Kamba's Table, and Ketan Gurih Ny. Lany. The research method used is descriptive qualitative. The results showed that the digital marketing strategy carried out by traditional products was to build a one stop shopping image on offline stores by sorting out some products that could be sold online, innovating products with special flavors, building confidence in consumers that the product was trusted and legendary, also endorsement of mass media (through television culinary programs) and positive testimonials from consumers who have used the product. In addition to direct marketing in stores (offline) where producers open outlets, the media used in the marketing of this Cirebon savory sticky rice are Instagram, whatsapp, line, SMS / Phone and online store (tokopedia / bukalapak). In the online store, product descriptions are described that only hold 1-3 days, and advice on the use of expedition services (shipping) that arrive quickly so that the product is still awake and good for consumption.
\end{abstract}

Keywords: digital marketing; traditional culinary products; Cirebon savory sticky rice; communication strategy.

\begin{abstract}
Abstrak
Strategi komunikasi pemasaran digital adalah suatu kegiatan promosi merek yang sudah direncanakan dan disusun secara sistematis. Strategi tersebut membangun interaksi merek dengan penggunaanya. Strategi pemasaran ini juga dilakukan oleh beberapa pelaku usaha kuliner tradisional khas Cirebon. Tujuan penelitian ini untuk menganalisis strategi komunikasi pemasaran pada tiga produsen ketan gurih Cirebon yaitu: Ketan Bumbu Ibu Yudi, Ketan Gurih Kamba's Table, Ketan Gurih Ny. Lany. Metode penelitian yang dilakukan adalah deskriptif kualitatif. Hasil penelitian menunjukkan bahwa strategi pemasaran digital yang dilakukan oleh produk tradisional ini yaitu membangun citra one stop shopping pada toko offline dengan memilah beberapa produk yang bisa dijual secara online, melakukan inovasi produk dengan citarasa khusus, membangun keyakinan terhadap konsumen bahwa produk terpercaya dan legendaris, juga melakukan endorsement media massa (melalui program kuliner televisi) serta testimoni positif dari konsumen yang sudah menggunakan produk tersebut. Selain pemasaran secara langsung di toko (offline) tempat produsen membuka gerai, media yang digunakan dalam pemasaran digital ketan gurih Cirebon ini
\end{abstract}


adalah instagram, whatsapp, line, SMS/ Telpon dan toko online (tokopedia/bukalapak). Pada toko online tersebut, dijabarkan deskripsi produk yang hanya tahan 1-3 hari, dan saran penggunaan jasa ekspedisi (pengiriman) yang cepat tiba agar produk masih terjaga dan baik untuk dikonsumsi.

Kata Kunci: digital marketing; produk kuliner tradisional; ketan gurih Cirebon; strategi komunikasi.

\section{PENDAHULUAN}

Komunikasi pemasaran (marketing Communication) dapat dinyatakan sebagai kegiatan komunikasi yang bertujuan untuk menyampaikan pesan pada konsumen dengan menggunakan berbagai media, dengan harapan agar komunikasi dapat menghasilkan perubahan pengetahuan, perubahan sikap, dan perubahan tindakan yang dikehendaki (Kennedy dan Soemanagara, 2009: 5). Menurut Hermawan (2012: 52), Integrated Marketing Communication (IMC) merupakan proses menyatukan perencanaan, tindakan dan koordinasi pada semua wilayah komunikasi pemasaran dan juga memahami konsumen menyangkut apa sebenarnya tanggapan konsumen. Menurut Hermawan (2012:54) bahwa bauran komunikasi pemasaran (juga disebut bauran promosi) terdiri dari lima alat utama yaitu periklanan, promosi penjualan, publisitas, direct marketing dan penjualan pribadi.

Strategi pemasaran ini juga dilakukan oleh beberapa pelaku usaha kuliner tradisional khas Cirebon. Sejak kunjungan wisatawan ke Cirebon semakin meningkat dengan adanya tol Cipali, pengembangan produk dan kuliner Cirebon semakin menggeliat. Cirebon semakin dikenal dengan ragam wisata kulinernya, di antaranya nasi jamblang, nasi lengko, empal gentong, empal asem, docang, kue tapel, sambel asem, krupuk mlarat dan banyak lagi. Selain kuliner tadi, salah satu makanan yang menjadi incaran para wisatawan di Cirebon adalah Ketan Gurih.

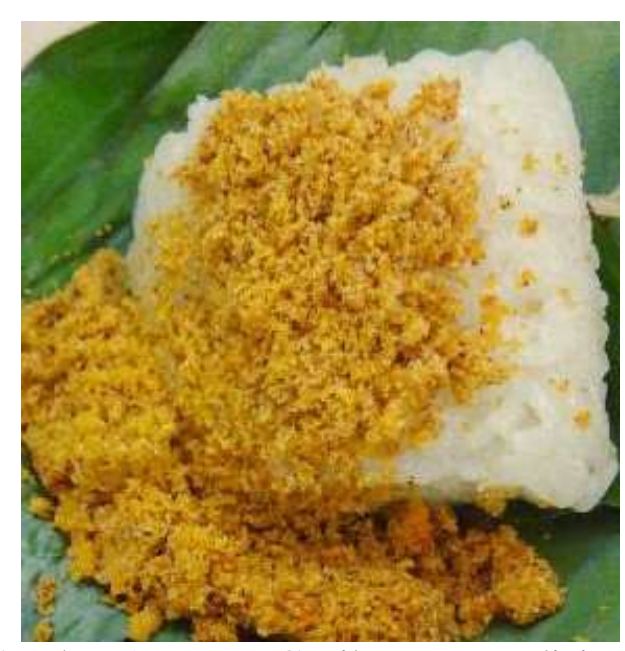

Gambar 1. Ketan Gurih, Kue Tradisional Khas Cirebon

Ketan gurih umumnya dikenal sebagai makanan tradisional di Jawa Barat dan Jawa Tengah. Ketan gurih khas Cirebon ini agak berbeda dengan yang lainnya, karena taburan khasnya. Ada taburan kelapa-gula sangrai, oncom sanggrai, kacang, hingga yang kekinian adalah ketan gurih bumbu ebi. Makanan ini merupakan kue basah atau jajanan tradisional yang legendaris bagi masyarakat. Rasanya enak, gurih, manis dan lezat membuat kue ini banyak diburu oleh masyarakat Cirebon.

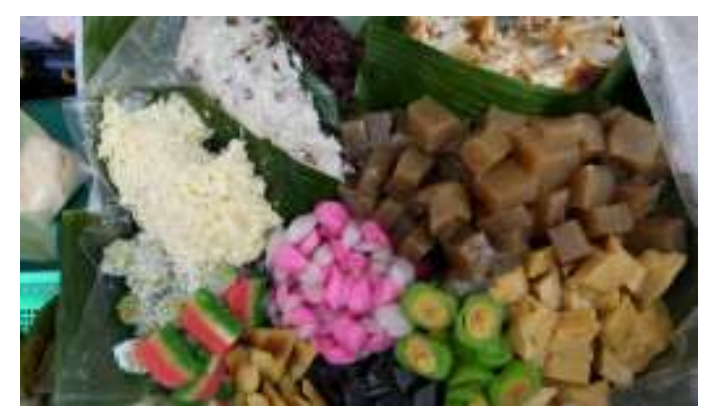

Gambar 2. Kue Jajanan Pasar Tradisional (Sumber gambar: www.wakuliner.com) 
Di pasar tradisional di Cirebon, ketan gurih dijual bersama kue tradisional lainnya seperti cenil, lupis, growol, ketan hitam, klepon, dan lainnya. Kue basah ini biasanya disimpan dalam tampah (nampan bambu), diberi taburan gula atau kelapa dan dibungkus dengan daun pisang. Khusus ketan gurih tradisional, biasanya hanya diberi taburan gula jawa dan kelapa sangrai yang dihaluskan. Adapun taburan bumbu oncom, kacang dan ebi; adalah pilihan bumbu ketan gurih yang merupakan pengembangan kuliner tradisional ini.

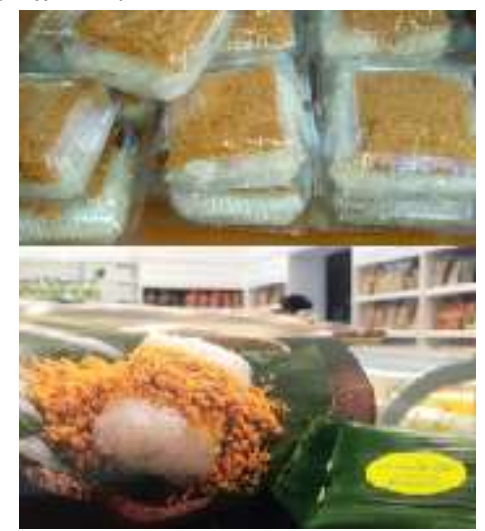

Gambar 3. Kemasan Ketan Gurih

Ketan gurih umumnya dikemas dengan daun pisang disemat lidi. Namun dengan alasan praktis, di pasar tradisional, kadang dibungkus dalam kemasan plastic mika kecil. Tren ketan gurih sebagai kuliner dan oleh-oleh khas daerah, membuat beberapa produsen ketan gurih Cirebon tak hanya mengembangkan produk, tapi juga cara pemasaran produk ini. Selain memasarkan produk di gerai oleh-oleh, ketan gurih juga dijual secara online.

Pemasaran secara online, dewasa ini banyak dipilih oleh para pelaku usaha. Hal ini dikarenakan, cara ini lebih mudah dan lebih memanfaatkan waktu secara efisien. Digital Marketing adalah sebuah media yang di gunakan untuk mempromosikan merk atau produk seseorang. Dengan memanfaat kan digital marketing, maka seseorang akan mendapat keuntungan dari bisnis yang di jalankan.

(http://digitalmarketinginaction.asia/)

Digital marketing saat ini memang lebih banyak memanfaatkan internet yang di gunakan sebagai media utama promosi produk yang dijual nya. Digital marketing adalah salah satu media yang cukup penting. Dimana, digital marketing di gunakan untuk mempromosikan suatu produk seseorang. Berbicara tentang digital, media yang digunakan dalam digital marketing adalah komputer, laptop, tablet dan smartphone. Dengan menggunakan digital marketing, maka pelaku usaha lebih mudah untuk mempromosikan produk yang dijual.

Perpaduan antara produk tradisional dengan cara pemasaran modern ini mendorong peneliti untuk mengkaji hal ini. Salah satunya, adalah mencari tahu bagaimana pelaku usaha dalam memasarkan produk tradisional dengan kemasan produk yang masih menggunakan daun pisang dan daya tahan tahan produk yang 1-3 hari melalui media digital? Media apa sajakah yang akan digunakan untuk pemasaran produk ini? Maka, peneliti memfokuskan penelitian ini pada Strategi Digital Marketing Produk Kuliner Tradisional Cirebon ini.

\section{TINJAUAN PUSTAKA}

Usaha Mikro, Kecil dan Menengah (UMKM) memiliki peran penting dalam laju ekonomi Indonesia terutama dalam penciptaan lapangan kerja dan pemberdayaan rumah tangga yang mendukung pendapatan rumah tangga. Keberadaan UMKM diharapkan mampu memacu perekonomian di tengah perlambatan ekonomi yang terjadi saat ini. Pemanfaatan konsep pemasaran berbasis teknologi digital (digital marketing) memberikan harapan bagi UMKM untuk berkembang menjadi pusat kekuatan ekonomi. Era digital memang tidak mungkin untuk dihindari. Pakar pemasaran 
Yuswohadi mengungkapkan bahwa jika ingin bertahan, maka pelaku UMKM harus mampu memaksimalkan manfaat perkembangan digital (Maulana, 2017).

Digital Marketing merupakan sebuah cara yang di gunakan untuk mempromosikan merk atau produk seseorang. Dengan memanfaatkan digital marketing, maka seseorang akan mendapat keuntungan dari bisnis yang di jalankan. Menjalankan bisnis memang tidak cukup mudah, sehingga banyak para pembisnis yang mencari cara untuk menjalankan bisnis tersebut. bisnis adalah salah satu hal yang sudah banyak di pilih seseorang untuk mencari keuntngan. Ada banyak bisnis yang sudah di pilih oleh seseorang, seperti menjual produk secara online. Cara online, banyak di pilih oleh seseorang. Hal ini di karenakan, cara ini lebih mudah dan lebih memanfaatkan waktu secara efisien. Digital marketing saat ini memang lebih banyak memanfaatkan internet yang di gunakan sebagai media utama promosi produk yang di jual nya. Digital marketing menjadi salah satu media yang cukup penting. Dimana, digital marketing di gunakan untuk mempromosikan suatu produk seseorang.

Digital marketing (Joseph, 2011: 32; Tan, 2016) merupakan suatu keadaan dimana pemasar harus menguasai tiga hal dari konsumen yaitu pikiran, hati dan semangat mengacu kepada pemasaran yang bersifat elektronik berbasis internet. Memacu pemasaran untuk menciptakan produk yang selain memberikan kualitas dan pelayanan juga memberikan pengalaman yang lebih kepada konsumen. Komunikasi pemasaran (Kennedy dan Soemanagara, 2009: 5) dapat dinyatakan sebagai kegiatan komunikasi yang bertujuan untuk menyampaikan pesan pada konsumen dengan menggunakan berbagai media, dengan harapan agar komunikasi dapat menghasilkan perubahan pengetahuan, perubahan sikap, dan perubahan tindakan yang dikehendaki.
Dapat dikatakan bahwa strategi komunikasi pemasaran digital adalah suatu kegiatan promosi merek yang sudah direncanakan dan disusun secara sistematis serta membangun interaksi merek dengan penggunaanya melalui aktivitas hiburan, kebudayaan, sosial atau aktivitas publik yang menarik perhatian lainnya menggunakan media baru atau digital pemasaran yang saat ini menjadi bagian penting dalam mencapai target konsumen (Tan, 2016). Tujuan promosi di antaranya membangun awareness, memberitahu (informatif), dan mengingatkan (remembering) (Kertajaya \& Setiawan, 2014).

Platform yang sering digunakan dalam digital marketing adalah media sosial atau jejaring sosial. Jejaring sosial yang tersedia terkadang memiliki karakteristik yang berbeda. Ada yang sifatnya untuk pertemanan seperti Facebook, Path, Instagram, dan Twitter, ada pula yang khusus untuk mencari dan membangun relasi seperti yang ditawarkan Linkedin. Selain itu tersedia pula media yang lebih pribadi seperti electronic mail (e-mail) dan pesan teks. Search engine seperti Google dan Yahoo pun dapat diberdayakan. Selain itu pelaku usaha juga dapat memanfaatkan media blog ataupun situs pribadi. (Purwana, 2017)\

\section{METODE PENELITIAN}

Penelitian ini menggunakan pendekatan deskriptif kualitatif. Penelitian ini bersifat penelitian deskriptif yakni penjabaran dari semua data yang terkumpul, dengan menggunakan metode kualitatif. Metode penelitian kualitatif didefinisikan sebagai metode penelitian ilmu-ilmu sosial yang mengumpulkan dan menganalisis data berupa kata-kata (lisan maupun tulisan) dan perbuatan-perbuatan manusia serte penelitian tidak menganalisa angka-angka. Penelitian ini menggunakan teknik observasi terhadap pelaku usaha ketan gurih di Cirebon dan media yang 
dikelola, mewawancarai informan dari produk/pelaku usaha yang, dan menelusuri kepustakaan tentang bahan-bahan yang terkait dengan kajian penelitian ini.

\section{HASIL PENELITIAN DAN PEMBAHASAN}

Salah satu produsen Ketan Gurih yang dikemas dengan modern yaitu Ketan Bumbu Ibu Yudi. Ketan Bumbu Ibu Yudi menjadi salah satu buah tangan khas Cirebon yang dikemas modern dan cantik dengan cita rasa menggugah selera. Ketan Bumbu Ibu Yudi ini merupakan buah tangan khas Cirebon yang bisa jadi teman santai untuk bernostalgia bersama keluarga. Atau, buah tangan untuk kembali lagi saat ke perantauan. Ketan bumbu ini dijual di toko kue Bonchery, Jl. Pamitran Cirebon.

Pengelola Bonschery, Giseyla mengatakan Ketan Bumbu Ibu Yudi merupakan inovasi produk ketan persembahan Toko Bonschery Cake and Bakery yang diolah dan diberi bumbu serundeng. Produknya pun dikemas dengan modern, cantik, serta cita rasa yang menggugah selera. Selain dijual di Bonschery, Ketan Bumbu Ibu Yudi juga tersedia di Toko Oleh-oleh Sinta, Toko Oleh-oleh Daud, Toko Oleh-oleh Ade, dan Empal Gentong H.Apud setiap hari Sabtu dan Minggu. Kalau di Toko Bonscherynya setiap hari tersedia. (www.radarcirebon.com, 3 Juli 2016)

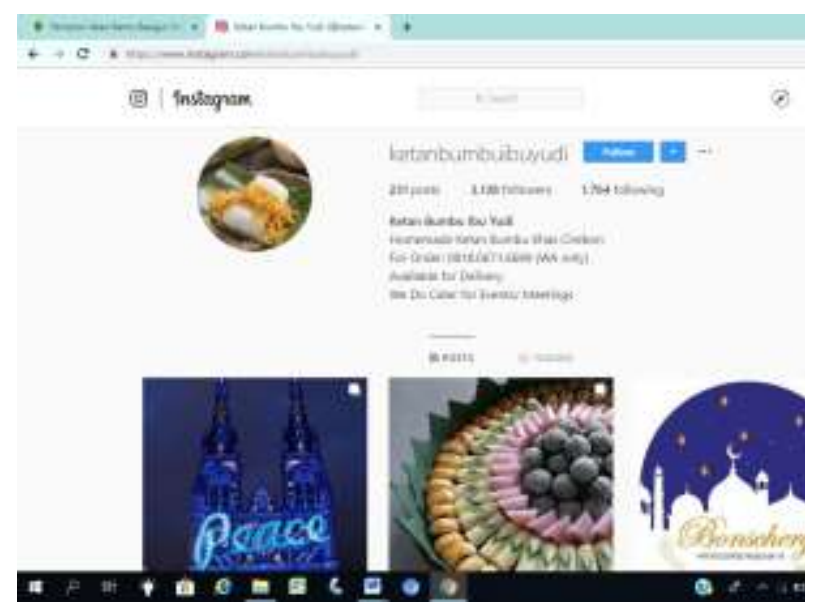

Gambar 4. Instagram Ketan Bumbu Ibu Yudi, Cirebon

Pengelola Bonschery, Giseyla mengatakan Ketan Bumbu Ibu Yudi merupakan inovasi produk ketan persembahan Toko Bonschery Cake and Bakery yang diolah dan diberi bumbu serundeng. Produknya pun dikemas dengan modern, cantik, serta cita rasa yang menggugah selera. Selain dijual di Bonschery, Ketan Bumbu Ibu Yudi juga tersedia di Toko Oleh-oleh Sinta, Toko Oleh-oleh Daud, Toko Oleh-oleh Ade, dan Empal Gentong H.Apud setiap hari Sabtu dan Minggu. Kalau di Toko Bonscherynya setiap hari tersedia. (www.radarcirebon.com, 3 Juli 2016)

Ketan Bumbu Ibu Yudi dijual satu boks dengan isi 5 buah, harga sebesar 7000 rupiah per buah. Cocok dijadikan oleh-oleh khas Cirebon. Toko ini biasanya meyiapkan stok lebih banyak untuk mengakomdir kebutuhan Ramadan. Selain Ketan Bumbu Ibu Yudi, produk oleh-oleh lainnya adalah Pia Gong yang juga tersedia di Bonschery. Pia Gong juga sangat cocok dijadikan oleh-oleh. Tersedia pia coklat, pia keju, pie susu, dan pie nanas. Kedua produk tersebut merupakan kue pelengkap yang dijual Bonschery selain aneka kue basah, kue kering, parsel, hingga menumenu berbuka puasa. Termasuk juga kue bolu loyangan seperti marmer cake yang selalu laris dari tahun ke tahun. Banyak jenis makanan yang dijual di Bonschery, secara tidak sengaja menjadikan Bonschery seperti one stop shopping. TokoBonchery terletak di Jalan Pamitran No.48 Cirebon. Buka setiap hari mulai jam 7 pagi sampai jam 6 sore. Sedangkan khusus di hari Minggu mulai jam 8 pagi sampai jam 4 sore. Ketan bumbu ini melakukan digital marketing melalui instagram dan whatsapp. Pada kemasan produk dan tampilan instagram Ketan Bumbu Ibu Yudi, ditampilkan nomor whatsapp yang bisa dihubungi untuk melakukan pemesanan online. 


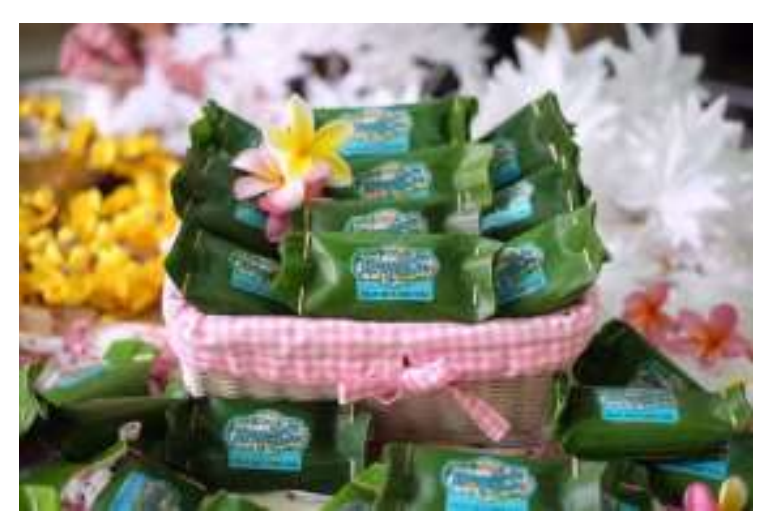

Gambar 5. Ketan Gurih Kamba's Table

Ketan Gurih Kamba's Table mengatakan awal mulanya saya membuat Ketan Gurih karena banyaknya wisatawan yang datang ke Kampoeng Batik EB Traditional yang menanyakan dimana ketan gurih dijual. Ia membuat tester dan setiap tamu diberi secara gratis. Dan semakin lama banyak diminati, bahkan ada yang sengaja membeli ketannya saja. (www.aboutcirebon.com)

Untuk membedakan dengan ketan gurih lain, pemilik Ketan Gurih Kamba's Table, Rere menginovasi untuk membuat ketan dengan bumbu ebi dan yang menjadi ciri khas Cirebon adalah udangnya. Harga jualnya pun lebih terangkau dan hanya Rp 5.500,-/bungkus. Ketan Gurih ini untuk dikonsumsi bisa tahan 1 hari jika tidak dimasukkan ke kulkas, namun jika dimasukkan ke kulkas bisa tahan 3 hari namun harus dipanaskan dengan microwave dulu. Pemilik Kamba's Table, meyakini Ketan Gurih ini akan booming sebagai salah satu oleh-oleh khas Cirebon untuk para wisatawan. Bahkan cemilan Ketan Gurih ini sudah booming di Jakarta dan mereka datang ke Cirebon pasti mencari Ketan Gurih ini. Gerai Ketan Gurih Kamba's Table ada di Jalan Panembahan Ratu, Plered Cirebon yang berada di Kawasan Batik EB Traditional.

Sejak kunjungan wisatawan ke Cirebon meningkat dengan adanya sejak ada Tol Cipali, salah satu kuliner yang menjadi incaran para wisatawan di Cirebon adalah Ketan Gurih. Salah satu produsen Ketan Gurih bermerk Ketan Gurih
Kamba's Table mengatakan awal mulanya membuat Ketan Gurih karena banyaknya wisatawan yang datang ke Kampoeng Batik EB Traditional yang menanyakan di mana ketan gurih dijual. Pemilik Ketan Gurih Kamba's Table coba membuat tester dan setiap tamu diberi secara gratis. Dan semakin lama banyak diminati, bahkan ada yang sengaja membeli ketannya saja. (http://www.radarcirebon.com, November 2016)

Pemilik Ketan Gurih Kamba's Table, Rere mengemukakan untuk membedakan dengan ketan gurih lain, pihaknya menginovasi untuk membuat ketan dengan bumbu ebi dan yang menjadi ciri khas Cirebon adalah udangnya. Harga jualnya pun lebih terangkau dan hanya $\mathrm{Rp}$ 5.500,-/bungkus. Ketan Gurih ini untuk dikonsumsi bisa tahan 1 hari jika tidak dimasukkan ke kulkas, namun jika dimasukkan ke kulkas bisa tahan 3 hari namun harus dipanaskan dengan microwave dulu. Cemilan ketan gurih ini sudah booming di Jakarta dan wisatawan domestic datang ke Cirebon biasanya mencari Ketan Gurih ini. Ketan Gurih Kamba's Table, dijual di Jalan Panembahan Ratu No. Plered Cirebon yang berada di Kawasan Batik EB Traditional. Ketan Gurih ini juga melakukan penjualan melalui whatsapp atau WA 081324995360 dan instagram IG @kambastable.

Selanjutnya, Ketan Gurih Ny. Lany, yang juga melakukan digital marketing melalui instagram, line dan whatsapp. Ketan Gurih / Ketan Bumbu di Toko Kue Ny Lany. Jl. Kesunean No. 3. Di kalangan masyarakat, kue ini banyak dijadikan oleholeh khas dari Cirebon, bahkan bisa melakukan order untuk wilayah Jakarta.

Selanjutnya, Ketan Gurih Ny. Lany, yang juga melakukan digital marketing melalui instagram, line dan whatsapp. Ketan Gurih / Ketan Bumbu di Toko Kue Ny Lany. Jl. Kesunean No. 3. Di kalangan masyarakat, 
kue ini banyak dijadikan oleh-oleh khas dari Cirebon, bahkan bisa melakukan order untuk wilayah Jakarta.

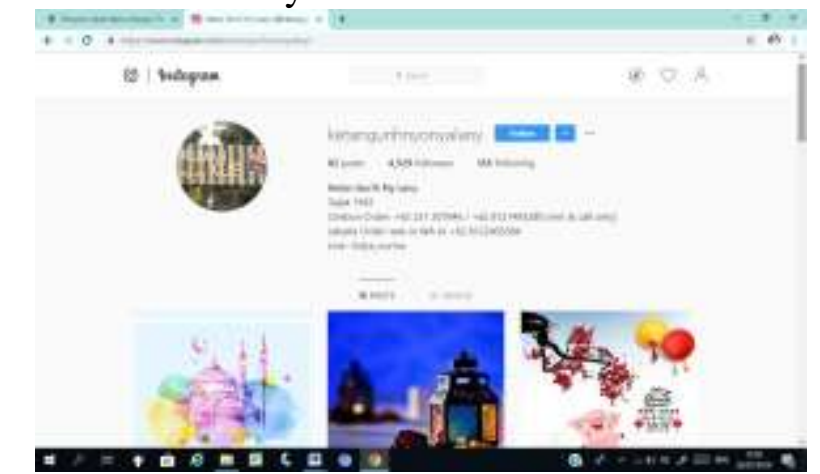

Gambar 6. Tampilan Akun Instagram Ketan Gurih Ny. Lany

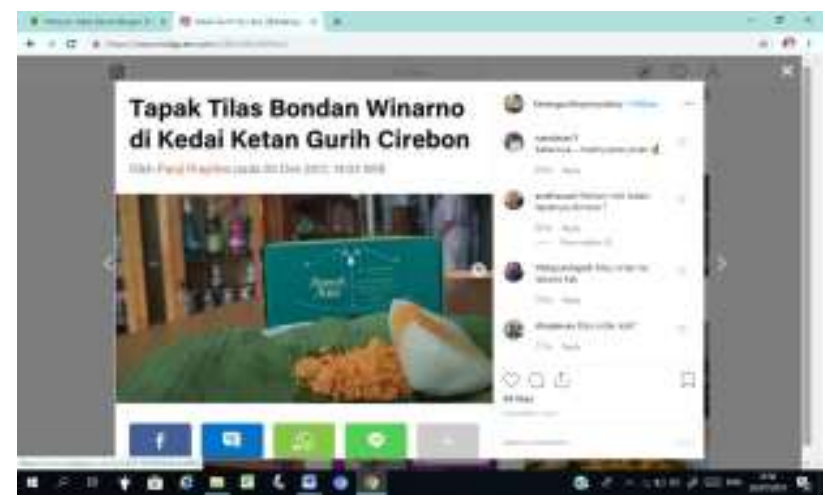

Gambar 7. Kemasan dan Salah Satu Postingan Ketan Bumbu Nyonya Lany di Instagram.

Ny. Lany cukup dikenal sebagai pelopor pembuat ketan gurih di kota Cirebon. Toko kuenya ada sejak tahun 1965. Bahkan, program televise kuliner yang dibawakan Bondan Winarno sempat mengangkat ketan gurih Ny Lany ini. Tayangan televisi tersebut seperti endorsement bagi produk kue tradisional ketan gurih Ny. Lany. Akun instagram Ketan Gurih Ny Lany tidak hanya berisi tentang produk, tapi juga ucapan-ucapan terkait perayaan hari besar tertentu. Akun ini juga seringkali me-repost gambar pada feed/kronologi dari akun konsumen yang menggunakan produknya. Hal ini ditujukan untuk menguatkan kepercayaan pelanggan atas testimony pengguna produk tersebut, dan menunjukkan bahwa brand (merek) Ketan Gurih Ny Lany terpercaya dan legendaris. Selain Instagram, pemilik kedai juga mengelola pesanan melalui whatsapp untuk wilayah Jakarta juga SMS (short message service) dan telpon untuk wilayah Cirebon. Ketan gurih ini juga bisa dipesan melalui line @listya_nurina. Langkah-langkah ini dilakukan pemilik kedai untuk memudahkan cara pemasaran produk kepada konsumen, dengan memanfaatkan sarana digital.

Selain produsen kuliner tersebut, ada juga pihak lain yang mengambil peluang dari keberadaan produk kuliner tersebut. Beberapa pedagang oleh-oleh membuka toko online di bukalapak dan tokopedia, mengambil produk ketan gurih Ny.Lany dan dijual kembali pada toko yang mereka kelola (reseller). Salah satunya adalah akun pedagang besar bernama "Oleh-Oleh Khas Cirebon" di bukalapak yang menjual makanan khas seperti pilihan oleh-oleh tradisional ketan gurih tersebut. Akun ini menjual ketan gurih Ny. Lany. Selain itu akun "Almahira" di tokopedia, juga berjualan oleholeh ketan gurih Ny. Lany. Pada toko online tersebut, dijabarkan deskripsi produk yang hanya tahan 1-3 hari, dan saran penggunaan jasa ekspedisi (pengiriman) yang cepat tiba agar produk masih terjaga dan baik untuk dikonsumsi.

Paparan di atas, peneliti sederhanakan dalam table berikut ini:

Tabel 1. Matriks Digital Marketing Tiga Produk Ketan Gurih Cirebon (2017)

\begin{tabular}{|c|c|c|c|}
\hline $\begin{array}{c}\text { Produ } \\
\text { sen } \\
\text { atau } \\
\text { Merk }\end{array}$ & $\begin{array}{c}\text { Media } \\
\text { Pemasar } \\
\text { an } \\
\text { Digital }\end{array}$ & $\begin{array}{c}\text { Konten } \\
\text { Pemasa } \\
\text { ran } \\
\text { Digital }\end{array}$ & Tujuan \\
\hline $\begin{array}{l}\text { Ketan } \\
\text { Bumbu } \\
\text { Ibu } \\
\text { Yudi }\end{array}$ & $\begin{array}{l}\text { Instagra } \\
\text { m, } \\
\text { Whatsap } \\
\text { p }\end{array}$ & $\begin{array}{l}\text { one stop } \\
\text { shoppin } \\
g\end{array}$ & $\begin{array}{l}\text { membang } \\
\text { un } \\
\text { awareness }\end{array}$ \\
\hline $\begin{array}{l}\text { Ketan } \\
\text { Gurih } \\
\text { Kamba } \\
\text { 's } \\
\text { Table }\end{array}$ & $\begin{array}{l}\text { Instagra } \\
\mathrm{m}, \\
\text { Whatsap } \\
\mathrm{p}\end{array}$ & $\begin{array}{l}\text { Inovasi } \\
\text { bumbu } \\
\text { ebi }\end{array}$ & $\begin{array}{l}\text { memberita } \\
\text { hu } \\
\text { (informati } \\
\text { f), } \\
\text { mengingat }\end{array}$ \\
\hline
\end{tabular}




\begin{tabular}{|c|c|c|c|}
\hline $\begin{array}{l}\text { Ketan } \\
\text { Gurih } \\
\text { Ny. } \\
\text { Lany }\end{array}$ & $\begin{array}{l}\text { Instagra } \\
\mathrm{m}, \\
\text { Whatsap } \\
\mathrm{p}, \\
\text { SMS/Tel } \\
\text { pon, } \\
\text { Line, } \\
\text { Tokopedi } \\
\text { a } \\
\text { (reseller) } \\
\text {, } \\
\text { Bukalapa } \\
\text { k } \\
\text { (reseller) }\end{array}$ & $\begin{array}{l}\text { produk } \\
\text { legendar } \\
\text { is, } \\
\text { terperca } \\
\text { ya, } \\
\text { endorse } \\
\text { ment } \\
\text { media } \\
\text { massa } \\
\text { (progra } \\
\text { m } \\
\text { kuliner } \\
\text { di } \\
\text { televisi), } \\
\text { testimon } \\
\text { i } \\
\text { konsume } \\
n\end{array}$ & $\begin{array}{l}\text { kan } \\
\text { (remembe } \\
\text { ring) }\end{array}$ \\
\hline
\end{tabular}

Dari tabel di atas, platform yang sering digunakan dalam digital marketing produk ini adalah media sosial instagram dan whatsapp. Instagram menjadi pilihan karena karakteristik tampilan yang didominasi gambar. Selain itu tersedia pula media yang lebih pribadi dan cepat dalam interaksi dua arah, yaitu whatsapp. Namun, media seperti line, SMS, telp dan toko online juga menjadi pilihan sarana pemasaran digital. Dari ketiga produk tersebut, tujuan digital marketing yang dilakukan untuk membangun awareness tentang tren produk kuliner tradisional yang jadi oleh-oleh khas Cirebon, memberitahu (informatif) tentang berbagai inovasi produk yaitu bumbu taburan, dan mengingatkan (remembering) tentang caracara atau tempat yang bisa dituju untuk bisa membeli produk tersebut.

\section{SIMPULAN}

Komunikasi pemasaran digital adalah suatu kegiatan promosi merek yang sudah direncanakan dan disusun secara sistematis serta membangun interaksi merek dengan penggunaanya melalui aktivitas hiburan, kebudayaan, sosial atau aktivitas publik yang menarik perhatian lainnya menggunakan media baru atau digital pemasaran yang saat ini menjadi bagian penting dalam mencapai target konsumen. Strategi pemasaran digital yang dilakukan oleh produk tradisional ini yaitu membangun citra one stop shopping pada toko offline dan memilah beberapa produk yang bisa dijual secara online, melakukan inovasi produk dengan citarasa khusus, membangun keyakinan terhadap konsumen bahwa produk terpercaya dan legendaris, juga melakukan endorsement media massa (program kuliner televisi) serta testimoni positif dari konsumen yang sudah menggunakan produk tersebut. Selain pemasaran secara langsung di toko (offline) tempat produsen membuka gerai, media yang digunakan dalam pemasaran digital ketan gurih Cirebon ini adalah instagram, whatsapp, line, SMS/ Telpon dan toko online (tokopedia/bukalapak). Pada toko online tersebut, dijabarkan deskripsi produk yang hanya tahan 1-3 hari, dan saran penggunaan jasa ekspedisi (pengiriman) yang cepat tiba agar produk masih terjaga dan baik untuk dikonsumsi.

\section{DAFTAR PUSTAKA}

Hermawan, Agus. 2012. "Komunikasi Pemasaran". Jakarta. Penerbit Erlangga.

Joseph, Thomas. 2011. APPS The Spirit of Digital Marketing 3.0. Jakarta: Penerbit PT Elex Media Komputindo.

Kertajaya, Hermawan \& Setiawan. 2014. WOW Marketing. Jakarta: Penerbit PT. Erlangga Pustaka Utama. Maulana, Y. 2017. http://swa.co.id/swa/csr-corner/.

Diakses melalui http://swa.co.id/: http://swa.co.id/swa/csrcorner/yuswo hady-ukm-harusmanfaatkanperkembangan-digital

Purwana, Dedi; R Rahmi \& Shandy Aditya. 2017. Pemanfaatan Digital Marketing Bagi Usaha Mikro, Kecil, Dan Menengah (UMKM) Di Kelurahan Malaka Sari, Duren Sawit. 
Vol 1 No 1, Jurnal Pemberdayaan Masyarakat Madani (JPMM) diakses melalui

http://journal.unj.ac.id/unj/index.php /jpm/article/view/1781

Setiawan, Nisa Amalina. 2014. Strategi Promosi dalam Pengembangan Pariwisata Lokal di Desa Wisata Jelekong. Jurnal Trikonomika Volume 13, No. 2, Desember 2014, Hal. 184-194.

Tan, Aulira M.; Martha Tri Lestari \& Dini Salmiyah Fithrah Ali. Respon Konsumen pada Strategi Komunikasi Pemasaran Digital Dinas Pariwisata Ekonomi Kreatif, Pemuda dan Olahraga Di Kawasan Wisata Mandeh Kabupaten Pesisir Selatan dalam e-Proceeding of Management : Vol.3, No.2 Agustus 2016 | Page 2631 diakses melalui https://openlibrary.telkomuniversity. ac.id/home/catalog/id/116379/slug/re spon-konsumen-pada-strategi- komunikasi-pemasaran-digital-dinaspariwisata-ekonomi-kreatif-pemudadan-olahraga-di-kawasan-wisatamandeh-kabupaten-pesisirselatan.html

Internet:

https://aboutcirebon.id/ketan-gurih-sudahmenjadi-incaran-wisatawan-di-cirebon/ https://www.tokopedia.com/kamptjaroeaba n/ketan-bumbu-kampoeng-tjaroeban-khaskota-cirebon

http://digitalmarketinginaction.asia/digitalmarketing-adalah-media-promosi/ https://www.wakuliner.com/blog/7-jajanpasar-yang-selalu-ada-dalam-tampah https://m.bukalapak.com/p/food/cemilansnack/8xdhid-jual-ketan-gurih-bumbu-ebi5-pc https://www.tokopedia.com/almahira12/ketan-bumbu-nylanny 